\title{
Identifying differences in GPs' working hours according to gender and employment position: A time sampling study using SMS text messaging
}

\author{
Daniël van Hassel ${ }^{* 1,2}$, Lud van der Velden ${ }^{1}$, Ronald Batenburg ${ }^{1,3}$ \\ ${ }^{1}$ NIVEL, Netherlands Institute for Health Services Research, Utrecht, The Netherlands \\ ${ }^{2}$ CAOP, Centre for Labour Relations in the Public Sector, The Hague, The Netherlands \\ ${ }^{3}$ Department of Sociology, Radboud University Nijmegen, Nijmegen, The Netherlands
}

Received: June 27, 2018

DOI: $10.5430 /$ ijh.v4n2p64
Accepted: September 3, $2018 \quad$ Online Published: September 16, 2018

URL: https://doi.org/10.5430/ijh.v4n2p64

\begin{abstract}
In order to aid health workforce planning, we measured the number of hours worked by general practitioners (GPs). The twofold aim of this study consisted of assessing the feasibility, validity and reliability of an innovative method to measure working time and, second, to analyse differences in hours worked between six types of GPs divided by the combination of their gender and employment position. Our method was based on multiple time point observations using SMS text messaging. On average 19 GPs participated every week for 57 weeks. In total 1,051 GPs participated resulting in 61,320 valid measurements of time use. On average, GPs worked 44 hours per week. About $56 \%$ of this time was spent on direct patient-related activities, $26 \%$ to indirect patient-related activities, and $18 \%$ to activities not related to patients. There were substantial differences in working hours between male and female self-employed, those drawing a salary from a duo or group practice and locum GPs. For example, male self-employed GPs worked 51.6 hours per week, whereas male locum GPs worked 26.7 hours per week. Generally, differences in hours worked with regard to gender and employment position are smaller if we relate these hours to the number of FTE they worked. Furthermore, we conclude that the method of SMS text messaging based on the time sampling technique presents a limited degree of interference to the participants' work and achieved reliable and valid results.
\end{abstract}

Key Words: General practitioners, Working hours, Workload, Workforce planning

\section{INTRODUCTION}

The working hours of general practitioners (GPs) is a key element in the debates surrounding workload and the quality of care both in the Netherlands and in other countries. ${ }^{[1-4]}$ This issue plays also a pivotal role in models of health workforce planning which have become an internationally acknowledged and applied instrument for controlling shortages and oversupply in the health labour market. ${ }^{[5,6]}$ The stock of health workers is a key parameter in health workforce models and is best measured not in headcounts but in the working time of the health workforce as this adjusts for part-time work. ${ }^{[7]}$

In the Netherlands the Advisory Committee on Medical Manpower Planning (in Dutch the "Capaciteitsorgaan") uses a planning model in which the capacity of GP care is expressed in full-time equivalents (FTEs) of GPs' work. ${ }^{[8]}$ It

\footnotetext{
*Correspondence: Daniël van Hassel; Email: d.hassel@nivel.nl; Address: NIVEL, Netherlands Institute for Health Services Research, P.O. Box 1568, 3500 BN Utrecht, The Netherlands.
} 
was not clear yet, however, if one FTE of for example a male self-employed GP, is comparable with one FTE of a female salaried GP. Therefore, we calculated the GP capacity specifically using the actual working hours in relation to FTE, and also account for gender and employment position.

Previous studies focussed, primarily, on the working hours of a GP practice, instead of on individual GPs ${ }^{[1,9]}$ or were aimed at measuring the working hours of self-employed GPs and not of locum GPs. ${ }^{[10]}$ Furthermore, in these and other studies, surveys and diaries were used which suffer from recall bias, ${ }^{[11]}$ low response rates, ${ }^{[12,13]}$ and a high administrative burden for respondents. ${ }^{[14,15]}$ Hence, we developed a method based on SMS to measure working hours more reliably and to avoid too great an administrative burden on GPs. GPs were questioned about their activities by sending SMS text messages at random moments according to the time sampling technique. The major advantage of this innovative method is that GPs report their activity easy, fast and in real time. ${ }^{[16,17]}$ Compared to other methods it also offers the least possible interference to GPs daily work.

The aim of this study is twofold. First, to assess the feasibility, validity and reliability of the method of SMS text messaging based on multiple time point observations. Second, to analyse the differences in hours worked between six types of GPs divided by the combination of their gender and employment position. In addition, the following main questions are addressed in this paper:

(1) How can the use of working hours by GPs be measured by SMS text messaging in a feasible, valid and reliable way?

(2) What are the differences in working hours between male and female self-employed, salaried and locum GPs?

\section{Methods}

\subsection{Data collection}

We measured the working hours in the period from December 2012 to January 2014. During this period we sent 5,028 invitations to 4,486 GPs who were registered in NIVEL's Dutch national registration of GPs. ${ }^{[18]}$ Part of the GPs was invited more than once in order to include enough GPs for the different subgroups. GPs could also subscribe for the study by e-mail in response to announcements published via websites and e-mails.

\subsection{The variables and the measurement tool}

We used an SMS application to question GPs at random about their activity during one week. The SMS text message asked the question: "What are you doing at this moment?" and included the time stamp the SMS was sent and four response categories (see Table 1).

Table 1. The four possible response categories

1. I am not working
2. I am undertaking an activity directly related to patients
For example: consultations, home visits or contact with
patients by email or phone.
3. I am undertaking an activity indirectly related to patients
For example: travelling to a patient, registration of patient
data, phone calls or consultations about patients.
4. I am undertaking an activity not related to patients
For example: training, financial administration of the
practice, administrative meetings.

The SMS application addressed this question once every three hours, throughout a 24-hour day. One reminder was sent by the application when no valid reply was received within half an hour. GPs reported, in advance, in which time slot they would not work and so no text messages were sent during that period. Prior to the week of SMS text messages, GPs completed a survey in which they indicated how many FTEs and how many hours they expected to work in the week that their working time would be measured. After the week of SMS text messages, we asked how many hours they had worked and how they had experienced their participation. GPs had the chance to verify and correct their responses afterwards by using an overview they received after the week of SMS text messages. This has resulted in ten to 20 e-mails with a small number of corrections, mainly regarding the type of activity.

\subsection{Analyses}

We weighted the results of our time-use study to the general population of GPs employed in the Netherlands in 2013 $(\mathrm{n}=11,075)$ regarding their gender, age and employment position. ${ }^{[18]}$

Working hours were measured in hours worked per week, based on the replies from the GPs to the SMS text messages sent during a week. In addition, we determined the number of working hours per FTE, by dividing the working hours measured by SMS during the week over the number of FTEs GPs had indicated in the initial survey. Through the survey, we asked GPs how many days or parts of a day they worked in one week, explaining that five days or ten parts of a day were counted as the average full-time GP job. This complies the international definition of FTE, that states that " $(. .$. full-time equivalent employment is the number of full-time equivalent jobs, defined as total hours actually worked by all employed persons divided by the average number of hours actually worked in full-time jobs". ${ }^{[19]}$ As working hours and 
number of working hours per FTE are the key dependent variables in the next analyses, we systematically present their confidence intervals in order to assess the reliability of the results.

\section{RESULTS}

\subsection{The response and representativeness of the partici- pants}

In total 1,051 GPs participated in the study, forty-four of them participated twice. This resulted in sufficient measurements to calculate reliably the average working hours per week for GPs and for the six subgroups, male and female self-employed, salaried and locum GPs. The composition of the response group corresponded reasonably well with the sample (see Table 2). Self-employed GPs participated more often, though we could include fewer locum GPs. We took this into account with the analyses.

Table 2. The numbers and distribution of participants and the GPs invited, by different characteristics*

\begin{tabular}{|c|c|c|c|c|}
\hline \multirow{2}{*}{ Item } & \multicolumn{2}{|c|}{ Participants SMS week } & \multicolumn{2}{|c|}{ Sample } \\
\hline & $\mathbf{N}$ & $\%$ & $\mathbf{N}$ & $\%$ \\
\hline \multicolumn{5}{|l|}{ Function } \\
\hline Self-employed & 642 & 58.6 & 2,300 & 45.7 \\
\hline Salaried & 214 & 19.5 & 1,027 & 20.4 \\
\hline Locum & 239 & 21.8 & 1,701 & 33.8 \\
\hline Total & 1,095 & 100 & 5,028 & 100 \\
\hline \multicolumn{5}{|l|}{ Gender } \\
\hline Male & 461 & 42.1 & 2,380 & 47.3 \\
\hline Female & 634 & 57.9 & 2,648 & 52.7 \\
\hline Total & 1,095 & 100 & 5,028 & 100 \\
\hline \multicolumn{5}{|l|}{ Age in years } \\
\hline$<40$ & 496 & 45.3 & 2,266 & 45.1 \\
\hline $40-49$ & 283 & 25.8 & 1,340 & 26.7 \\
\hline $50-59$ & 268 & 24.5 & 1,129 & 22.5 \\
\hline$\geq 60$ & 48 & 4.4 & 293 & 5.8 \\
\hline Total & 1,095 & 100 & 5,028 & 100 \\
\hline Mean age in years & 42.8 & & 43.1 & \\
\hline $\begin{array}{l}\text { Note. "We took a stratified } \\
\text { employment position and ge } \\
\text { of GPs or the survey which } \\
\text { GPs were invited more than } \\
\text { SMS weeks. Participants co } \\
\text { percentages could deviate as }\end{array}$ & $\begin{array}{l}\text { as condu } \\
\text { nce whil } \\
\text { cern the a } \\
\text { a result of }\end{array}$ & $\begin{array}{l}\text { opulation of GPs } \\
\text { istics are based } \\
\text { re the weeks of } \\
\text { have also particip } \\
\text { not active invit } \\
\text { g up or down. }\end{array}$ & $\begin{array}{l}\text { a different } \\
\text { NIVEL r } \\
\text { text messa } \\
\text { more than } \\
\text { s. The sun }\end{array}$ & $\begin{array}{l}\text { hance by } \\
\text { istration } \\
\text { ng. Some } \\
\text { ice in the } \\
\text { of the }\end{array}$ \\
\hline
\end{tabular}

On average 19 GPs participated in every week of the SMS text messages. These included more women (11) than men (eight) which corresponded with the composition of our sample. On average 11 self-employed, four salaried and four locum GPs participated in every week.

More detailed information of the sample and response is described elsewhere. ${ }^{[16]}$

\subsection{Response on the SMS text messages}

The SMS application programmed 61,320 activity messages to be sent to the 1,051 GPs. Of these, approximately 27,000 messages were actually sent as GPs could unsubscribe for certain periods of time. The activity messages which were not sent were mostly programmed during evenings, nights or in the weekend. These measurements counted as moments GPs did not work (see also section "The variables and the measurement tool").

We received a valid reply from $94 \%$ of the activity messages in total. Approximately $80 \%$ of the SMS text messages were replied to within one hour, $51 \%$ within 10 minutes. GPs reported positive experiences about the way their use of time was measured and, in particular, they indicated that the SMS text messages resulted in limited interference to their work.

\subsection{The number of working hours}

As is shown in Table 3, the participating GPs worked 44 hours per week on average. Self-employed GPs worked 49.4 hours, 17 hours more than salaried GPs who worked 32.7 hours, and approximately 19 hours more than locum GPs who worked 29.9 hours. Male GPs worked six to seven hours more than female ones in the categories self-employed GPs and salaried GPs. Regarding the employment position of locum GPs, it becomes clear that men worked five hours fewer than women. It is also shown that the participating men work eight hours more than their female counterparts regardless of their employment position. Generally, the confidence intervals for the averages are small.

\subsection{The number of hours per FTE}

Figure 1 shows that on average, the participating GPs worked 57.1 hours per FTE, i.e. if they would work all parts of the day and during the whole week. Again, there are large differences between the types of GPs. For instance, self-employed GPs worked 60.5 hours per FTE while salaried GPs worked 49.9 hours per FTE.

In most cases, the subgroup differences for working hours per FTE are smaller than the subgroup differences for the actual number of working hours, as shown earlier (see Table 4). For example, male self-employed GPs worked nine hours per FTE more than female salaried GPs, while this is almost twenty hours for the actual number of working hours. A reverse result is that the difference between female self-employed GPs and male salaried GPs or female locum GPs is larger for working hours per FTE than for the actual working hours per week. 
Table 3. GPs average number of working hours per week including the $95 \%$ confidence interval $(95 \% \mathrm{CI})$ calculated on the basis of the SMS measurements, per type of activity divided by employment position and gender*

\begin{tabular}{|c|c|c|c|c|c|c|c|c|c|c|}
\hline \multirow{2}{*}{ Items } & & \multirow{2}{*}{$\begin{array}{l}\text { Weighted } \\
\text { number } \\
\text { of GPs }\end{array}$} & \multicolumn{2}{|c|}{ Direct patient related } & \multicolumn{2}{|c|}{ Indirect patient related } & \multicolumn{2}{|c|}{ Not related to patients } & \multicolumn{2}{|c|}{ Total } \\
\hline & & & Hours & $95 \%$-CI & Hours & $95 \%$-CI & Hours & $95 \%$-CI & Hours & $95 \%-C I$ \\
\hline \multirow{3}{*}{$\begin{array}{l}\text { Self- } \\
\text { employed }\end{array}$} & M & 4,875 & 29.3 & $(28.2-30.5)$ & 13.6 & (12.6-14.6) & 8.6 & $(7.7-9.6)$ & 51.6 & $(49.7-53.4)$ \\
\hline & $\mathrm{F}$ & 3,019 & 22.8 & $(21.9-23.7)$ & 12.4 & $(11.6-13.2)$ & 10.6 & $(9.6-11.5)$ & 45.8 & $(44.3-47.3)$ \\
\hline & $\mathrm{T}$ & 7,894 & 26.8 & $(26.0-27.7)$ & 13.1 & $(12.5-13.8)$ & 9.4 & $(8.7-10.1)$ & 49.4 & $(48.1-50.6)$ \\
\hline \multirow{3}{*}{ Salaried } & M & 120 & 23.8 & (21.1-26.6) & 9.0 & $(7.1-11.0)$ & 6.1 & $(4.0-8.2)$ & 38.9 & $(34.9-43.0)$ \\
\hline & $\mathrm{F}$ & 851 & 18.9 & $(17.8-20.1)$ & 7.3 & $(6.4-8.2)$ & 5.6 & $(4.7-6.6)$ & 31.8 & $(30.2-33.5)$ \\
\hline & $\mathrm{T}$ & 971 & 19.5 & $(18.5-20.6)$ & 7.5 & $(6.7-8.3)$ & 5.7 & $(4.8-6.5)$ & 32.7 & (31.2-34.3) \\
\hline \multirow{3}{*}{ Locum } & M & 895 & 18.7 & $(9.7-27.6)$ & 4.7 & $(2.6-6.9)$ & 3.3 & $(1.8-4.9)$ & 26.7 & $(14.3-39.1)$ \\
\hline & $\mathrm{F}$ & 1,315 & 19.4 & $(17.4-21.4)$ & 7.6 & $(6.2-9.1)$ & 5.0 & $(3.9-6.1)$ & 32.0 & $(28.8-35.2)$ \\
\hline & $\mathrm{T}$ & 2,210 & 19.1 & $(15.1-23.0)$ & 6.5 & $(4.8-8.1)$ & 4.3 & $(3.2-5.5)$ & 29.9 & $(23.6-36.1)$ \\
\hline \multirow{3}{*}{ Total } & M & 5,890 & 27.6 & $(25.0-30.2)$ & 12.2 & $(10.7-13.6)$ & 7.8 & (6.7-8.8) & 47.5 & (42.9-52.1) \\
\hline & F & 5,185 & 21.3 & $(20.5-22.1)$ & 10.4 & $(9.7-11.0)$ & 8.3 & $(7.7-9.0)$ & 40.0 & (38.6-41.4) \\
\hline & $\mathrm{T}$ & 11,075 & 24.6 & (23.4-25.9) & 11.3 & $(10.5-12.1)$ & 8.0 & $(7.4-8.7)$ & 44.0 & (41.6-46.4) \\
\hline
\end{tabular}

Note. ${ }^{*} \mathrm{~N}=61,320$ measurements, 1,095 weeks of measurement, 1,051 GPs. The sum of the hours per type of activity could deviate from the total hours as a result of rounding up or down. The results are weighted on the bases of population numbers by employment position, gender and age. $\mathrm{M}=$ male, $\mathrm{F}=$ female, $\mathrm{T}=$ total.

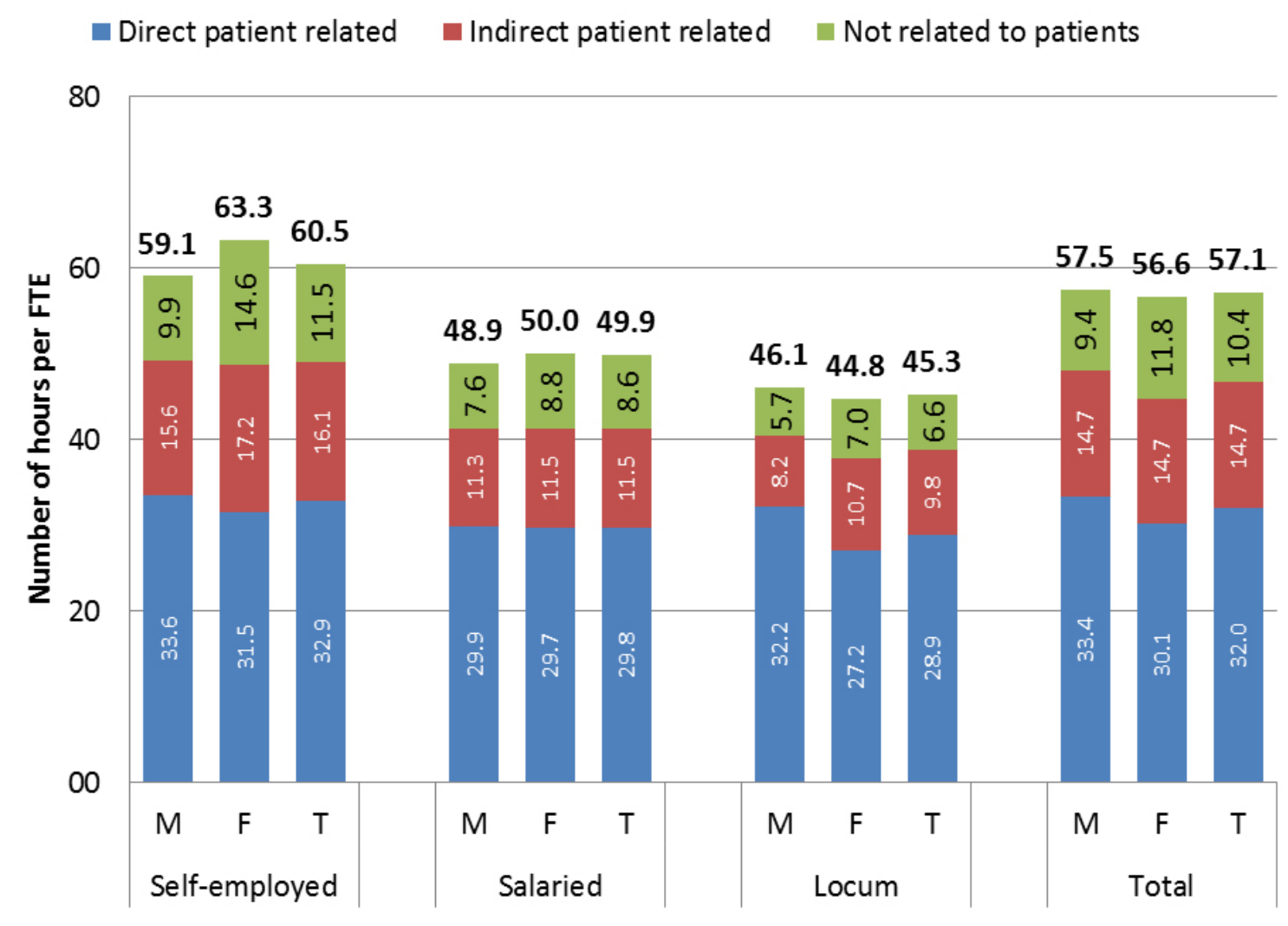

Figure 1. The number of hours per FTE spent on working as a GP based on the SMS measurements, per type of activity by employment position and gender

$N=61,320$ measurements, 1,095 SMS weeks of measurement, 1,051 GPs. The sum of the hours per type of activity could deviate from the total hours as a result of rounding up or down. The results are weighted on the bases of population numbers by employment position, gender and age. Based on the average FTE GPs indicated in the survey prior to the weeks of measurement. $M=$ male, $F=$ female, $T=$ total. 


\subsection{Proportion of hours per activity}

GPs spent $56 \%$ of their working hours on direct patientrelated activities, $26 \%$ on indirect patient-related activities and $18 \%$ on activities not related to patients (see Figure 2).

Self-employed GPs spent relatively fewer hours on direct patient-related activities: $54 \%$ versus $60 \%$ of salaried GPs and $64 \%$ of locum GPs. Naturally, self-employed GPs spent more time on activities indirectly related, and not related, to patients. Further broken down, it appears that specifically female self-employed GPs spent a smaller part of their working time on direct patient-related activities compared to their male peers in the same working position (50\% versus $57 \%$ ) and a larger part on non-patient related activities (23\% versus $17 \%$ ). This gender difference is also shown by the other two employment positions.

Table 4. The differences in working hours per FTE and actual working hours, between the six types of GPs according to their gender and employment position (based on the results shown in Table 3 and Figure 1)*

\begin{tabular}{|c|c|c|c|c|c|c|c|c|c|c|c|}
\hline \multicolumn{12}{|c|}{ Reference group (column minus row) } \\
\hline \multirow{2}{*}{\multicolumn{2}{|c|}{ Items }} & \multicolumn{2}{|c|}{ Self-employed (M) } & \multicolumn{2}{|c|}{ Self-employed (F) } & \multicolumn{2}{|c|}{ Salaried (M) } & \multicolumn{2}{|c|}{ Salaried (F) } & \multicolumn{2}{|c|}{ Locum (M) } \\
\hline & & Hours/FTE & Hours & Hours/FTE & Hours & Hours/FTE & Hours & Hours/FTE & Hours & Hours/FTE & Hours \\
\hline \multirow{2}{*}{$\begin{array}{l}\text { Self- } \\
\text { employed }\end{array}$} & M & & & & & & & & & & \\
\hline & $\mathrm{F}$ & -4.3 & 5.8 & & & & & & & & \\
\hline \multirow{2}{*}{ Salaried } & M & 10.1 & 12.6 & 14.4 & 6.9 & & & & & & \\
\hline & $\mathrm{F}$ & 9.0 & 19.7 & 13.3 & 13.9 & -1.1 & 7.1 & & & & \\
\hline \multirow{2}{*}{ Locum } & M & 12.9 & 24.8 & 17.2 & 19.1 & 2.8 & 12.2 & 3.9 & 5.1 & & \\
\hline & $\mathrm{F}$ & 14.2 & 19.6 & 18.5 & 13.8 & 4.1 & 6.9 & 5.2 & -0.2 & 1.3 & -5.3 \\
\hline
\end{tabular}

Note. ${ }^{*}$ The hours of the types of GPs presented in the rows of the table are subtracted from the hours of the types of GPs presented in the columns of the table (= reference group). For example, the results show that male self-employed GPs (first column) are working 4.3 hours per FTE fewer, and 5.8 working hours more, than female self-employed GPs (first row). Hours/FTE $=$ average number of working hours per FTE, Hours = average number of working hours per week. Bolt = subgroup difference in hours per FTE is smaller than subgroup difference in actual working hours. Cursive = subgroup difference in hours per FTE is larger than the subgroup difference in actual working hours. Not bolt or cursive = subgroup difference in hours per FTE is positive while the subgroup difference in actual working hours is negative; or vice versa. $\mathrm{M}=$ male, $\mathrm{F}=$ female.

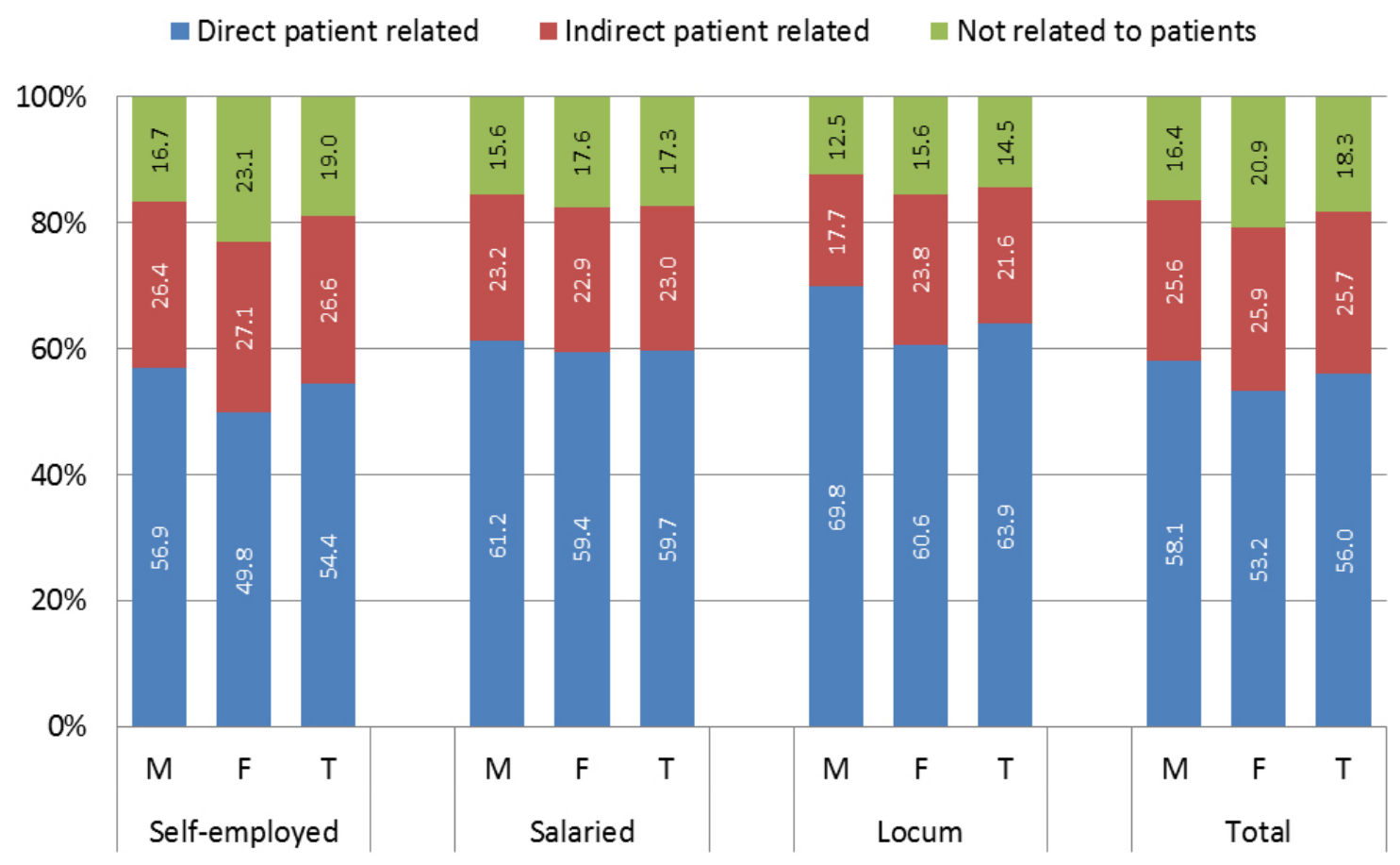

Figure 2. The percentage of the working hours spent on working as a GP based on the SMS measurements, per type of activity by employment position and gender

$N=61,320$ measurements, 1,095 SMS weeks of measurement, 1,051 GPs. The sum of the percentages per type of activity could deviate from $100 \%$ as a result of rounding up or down. The results are weighted on the bases of population numbers by employment position, gender and age. 


\subsection{A comparison of the SMS data with the survey data}

The total number of working hours we calculated on the basis of the SMS data was, for all subgroups, approximately four to nine hours per week higher than the number of hours GPs indicated in the survey prior to the weeks of SMS text messages (see Table 5). The SMS-based calculation also showed a higher total number of working hours compared to the survey taken after the SMS week, but this difference was smaller. By both surveys particularly the time spent on activities indirectly related, and not related, to patients were underestimated.

Table 5. Absolute and relative differences between working hours measured by SMS text messages and the mean working hours GPs indicated in the pre- and post-surveys, by type of activity for the six types of GPs*

\begin{tabular}{|c|c|c|c|c|c|c|c|c|c|c|c|c|c|c|c|c|c|}
\hline \multirow{3}{*}{ Items } & & \multicolumn{4}{|c|}{ Direct patient related } & \multicolumn{4}{|c|}{ Indirect patient related } & \multicolumn{4}{|c|}{ Not related to patients } & \multicolumn{4}{|c|}{ Total hours } \\
\hline & & \multicolumn{2}{|c|}{$\begin{array}{l}\text { SMSdata- } \\
\text { presurv }\end{array}$} & \multicolumn{2}{|c|}{$\begin{array}{l}\text { SMSdata- } \\
\text { postsurv }\end{array}$} & \multicolumn{2}{|c|}{$\begin{array}{l}\text { SMSdata- } \\
\text { presurv }\end{array}$} & \multicolumn{2}{|c|}{$\begin{array}{l}\text { SMSdata- } \\
\text { postsurv }\end{array}$} & \multicolumn{2}{|c|}{$\begin{array}{l}\text { SMSdata- } \\
\text { presurv }\end{array}$} & \multicolumn{2}{|c|}{$\begin{array}{l}\text { smsdata- } \\
\text { postsurv }\end{array}$} & \multicolumn{2}{|c|}{$\begin{array}{l}\text { SMSdata- } \\
\text { presurv }\end{array}$} & \multicolumn{2}{|c|}{$\begin{array}{l}\text { SMSdata- } \\
\text { postsurv }\end{array}$} \\
\hline & M & -0.3 & $(-1 \%)$ & -1.5 & $(-5 \%)$ & 3.6 & $(37 \%)$ & 2.7 & $(25 \%)$ & 2.6 & $(42 \%)$ & 1.5 & $(20 \%)$ & 5.9 & (13\%) & 2.7 & $(6 \%)$ \\
\hline \multirow{3}{*}{$\begin{array}{l}\text { Self- } \\
\text { employed }\end{array}$} & F & -0.3 & $(-1 \%)$ & -1.0 & $(-4 \%)$ & 4.3 & (54\%) & 3.1 & (34\%) & 5.3 & (95\%) & 3.6 & (49\%) & 9.2 & (25\%) & 5.7 & $(14 \%)$ \\
\hline & $\mathrm{T}$ & -0.3 & $(-1 \%)$ & -1.3 & $(-5 \%)$ & 3.9 & $(43 \%)$ & 2.9 & $(28 \%)$ & 3.6 & $(61 \%)$ & 2.3 & (31\%) & 7.2 & $(17 \%)$ & 3.8 & (8\%) \\
\hline & M & 0.6 & (2\%) & -1.3 & $(-5 \%)$ & 3.1 & (55\%) & 1.8 & (27\%) & 2.3 & (57\%) & 2.3 & (57\%) & 6.0 & $(18 \%)$ & 2.9 & (8\%) \\
\hline \multirow[t]{3}{*}{ Salaried } & $\mathrm{F}$ & 1.3 & $(8 \%)$ & -0.3 & $(-2 \%)$ & 1.4 & (23\%) & 1.3 & (23\%) & 2.5 & (81\%) & 1.5 & $(36 \%)$ & 5.2 & (20\%) & 2.5 & (9\%) \\
\hline & $\mathrm{T}$ & 1.2 & (7\%) & -0.4 & $(-2 \%)$ & 1.6 & $(27 \%)$ & 1.4 & (23\%) & 2.5 & (77\%) & 1.6 & (38\%) & 5.3 & (19\%) & 2.5 & (8\%) \\
\hline & $\mathrm{M}$ & 1.2 & (5\%) & -1.0 & $(-4 \%)$ & 1.1 & (19\%) & 0.5 & (8\%) & 2.1 & (73\%) & 1.5 & (45\%) & 4.4 & (13\%) & 1.0 & (3\%) \\
\hline \multirow[t]{3}{*}{ Locum } & $\mathrm{F}$ & 0.1 & $(1 \%)$ & -0.9 & $(-4 \%)$ & 2.5 & (44\%) & 1.3 & (20\%) & 2.5 & (94\%) & 1.0 & (26\%) & 5.1 & (18\%) & 1.5 & (5\%) \\
\hline & $\mathrm{T}$ & 0.5 & (2\%) & -0.9 & $(-4 \%)$ & 2.1 & (37\%) & 1.1 & (16\%) & 2.4 & (88\%) & 1.2 & (31\%) & 4.9 & (16\%) & 1.4 & (4\%) \\
\hline & M & -0.1 & $(-1 \%)$ & -1.5 & (-5\%) & 3.3 & (36\%) & 2.5 & (24\%) & 2.5 & (44\%) & 1.5 & (22\%) & 5.7 & (13\%) & 2.5 & (5\%) \\
\hline \multirow[t]{2}{*}{ Total } & $\mathrm{F}$ & 0.1 & $(0 \%)$ & -0.8 & $(-4 \%)$ & 3.4 & (48\%) & 2.4 & (30\%) & 4.1 & (93\%) & 2.6 & (44\%) & 7.6 & (23\%) & 4.1 & (11\%) \\
\hline & $\mathrm{T}$ & 0.0 & $(0 \%)$ & -1.2 & $(-4 \%)$ & 3.4 & (41\%) & 2.4 & (27\%) & 3.3 & $(64 \%)$ & 2.0 & (32\%) & 6.6 & $(17 \%)$ & 3.3 & (8\%) \\
\hline
\end{tabular}

Note. ${ }^{*} \mathrm{~N}=53,536$ measurements, 956 weeks of measurement, 915 GPs. The sum of the hours per type of activity could deviate from the total hours as a result of rounding up or down. The results are weighted on the bases of population numbers by employment position, gender and age. $\mathrm{M}=$ male, $\mathrm{F}=$ female, $\mathrm{T}=$ total.

\section{Discussion}

We used a method of SMS text messages based on the time sampling technique in order to gain insight into the differences in working hours between different types of GPs divided up by their gender and employment position. Every GP was sent 56 SMS text messages per week at random moments in time slots of three hours which provide a rough estimate of their individual working hours. For the six different subgroups of GPs, based on their gender and employment position, the number of measurements is much higher which improves the reliability of the results considerably. This was shown by the relatively small confidence intervals of the mean working hours per week. Regarding the validity of the results, an important indicator is that a valid reply was received from $94 \%$ of all the activity messages we sent and $80 \%$ of the replies to all messages were received within one hour. This shows that recall bias had played a minor role in our study. Another important finding is that GPs were mainly positive about the SMS tool and that they experienced limited interference from the messages they had to reply during their working week.

The results of the SMS measurements showed that the average participating GP worked 44 hours per week. Male self- employed GPs worked the highest number of hours (51.6) while male locum GPs worked the lowest number of hours (26.7). Generally, the subgroup differences in working hours were smaller if we relate them to the number of FTEs the GPs indicated to work. On average, the participating GPs spent $56 \%$ of their hours on activities directly related to patients, $26 \%$ on indirectly related ones and $18 \%$ on activities not related to patients.

\subsection{Comparison with other research}

Our results can, in part, be compared with those from other studies. A diary study by the association for self-employed GPs, the Vereniging Praktijkhoudende Huisartsen, conducted in 2012, showed that self-employed GPs (including other salaried GPs and locum GPs working in their practice), worked 66.1 hours per week, standardized for the size of a practice consisting of 2,350 patients in the Netherlands at that time. ${ }^{[9]}$ If we relate this to the results of our SMS-based study, it shows that GPs worked 69.9 hours per week per standard practice in 2013 (see Table 6).

A survey by IQ Health Care and the Dutch College of General Practitioners the "Nederlands Huisartsen Genootschap" in 2011, showed that GPs (independent of their working 
week in FTE) worked 44 hours per week on average; which is the same as the results of our study. ${ }^{[1]}$ Furthermore, the average working hours of Dutch GPs are slightly different from other Western countries, such as Canada (42.5) and the United Kingdom (42.2), uncorrected for the contracted working hours or FTEs they worked. ${ }^{[20]}$

Finally, our results showed that self-employed GPs worked, on average, 49.4 hours a week. This is highly comparable with the results of the QUALICOPC project for Dutch self-employed GPs held in 2012, which arrive at a figure of almost 48 hours, including out-of-office hours. ${ }^{[21]}$

Table 6. An explanation of the calculation of working hours of the SMS study to hours per standard practice

The number of 11,075 employed GPs on the 1st of January 2013
was multiplied by 44 - the average number of working hours per
week. This total number of working hours was divided by the total
number of patients registered in the Netherlands on the 1 st of
February 2013 according to the annual report of the foundation
which registers patients the "Jaarverslag Stichting Inschrijving Op
Naam"; 16.375 million. By multiplying this result by 2,350 , the
number of patients of a standard practice, it can be shown that GPs
work: $((11,075 \times 44) / 16,375,000) \times 2,350=69.9$ hours per week
for a standard practice.

\subsection{The workload of GPs}

Many GPs, both in the Netherlands and in other countries, are experiencing a high workload. They are seriously worried about the quality of GP care which is under pressure due to increasing registration tasks and administration. ${ }^{[22,23]}$ We did not measure or study the work pressure Dutch GPs experience, but the weekly working hours we measured do provide an indication of the objective work pressure of GPs. We showed that GPs worked approximately 57.1 hours per FTE, while almost one fifth of their hours was spent on activities not related to their patients. The question is to what extent this will change in the near future. In the period after we completed our study, several adaptations in the organisation of Dutch healthcare were made which will probably have an impact upon the work of GPs. For example, since the 1 th of January 2015, local authorities have more responsibilities for organising the care for people with disabilities or those with mental health problems in order to enable them to remain living at home as long as possible. This could result in more and longer consultations from these people and a higher workload for GPs. On the other hand, previous research has shown that between 1987 and 2001, the number of consultations increased while GPs had managed to keep a cap on their working hours by organising their work differently, such as by employing more support staff. ${ }^{[4]}$ Hence, new and repeated measurements of GPs, and possibly of their support staff, is needed in order to show to what extent these kinds of organisational changes, both within and outside of general practice, have an impact upon GPs working hours.

Another key finding of this study was that GPs worked more hours than they had indicated in the survey taken before and after the SMS weeks. Specifically, the hours measured for those tasks which were indirectly related to patients, and for those not related to patients, are higher than those which GPs had reported in the surveys conducted surrounding the weeks of the SMS text messages. This suggests that a part of their workload and specifically the activities not, or indirectly, related to patients, is, in reality, higher than they had indicated. A possible explanation for this finding is that GPs did not register these activities in their agendas and because it is more difficult to register or replicate them compared to activities directly related to patients.

\subsection{Limitations}

Some limitations to this study have to be taken into account. Firstly, the hours measured are representative of a "normal" working week while GPs could have worked fewer hours, for instance when they had some days off. Weeks in which GPs had no working days at all were not taken into account. This means that the average number of hours measured is representative of one of the 47 working weeks per year that GPs normally work. Secondly, we weighted the working hours of GPs by their employment position, gender and age of the population. Further research is needed among other variables that could have an impact upon working hours, for example with regard to the type of practice and the GPs' employment location. Thirdly, the results could be biased if GPs had replied to an SMS text message later in time than the actual moment of measurement. In most cases it could be expected that GPs would complete their activity first before they reply to an SMS text message. This applies particularly to the activities directly related to patients. On the other hand, as has been noted earlier, a large part of the activity messages were replied to within one hour. The SMS text message with the question: "What are you doing?" also included the time stamp of the moment the message was programmed and sent. Furthermore, GPs received an overview of their answers afterwards and only a few GPs reported some corrections.

\section{Conclusions}

We conclude that measuring working hours with SMS text messaging, together with our time sampling design, requires a minimal effort from the participants on the one hand and achieves reliable and valid results on the other. Considering these positive results, the method is recommended to healthcare managers, workforce planners and researchers in 
different countries who need to gain insight into the working hours of GPs or other healthcare professionals. Furthermore, the results of this study of time-use showed large differences in the working hours between different subgroups of GPs divided by their employment position and gender. Generally, these differences were smaller if we related the working hours to the number of FTEs they worked. For the intake of Dutch GPs, which will be recommended by the Advisory Committee on Medical Manpower Planning, it underlines the importance of making a distinction by gender but also by the employment position they hold, both now and in the future.

\section{FUNDING}

The original study was funded by the Advisory Committee on Medical Manpower Planning (Capaciteitsorgaan).

\section{Disclosure}

A different and shorter version of this paper was published in Dutch: Van Hassel D, Van der Velden, L, Batenburg R. Diversiteit in de tijdsbesteding van huisartsen. Huisarts en wetenschap. 2016; 59: 150-154.

\section{CONFlicts of InTEREST Disclosure}

The authors declare that they have no conflict of interests.

\section{REFERENCES}

[1] Braspenning JCC, Van Doorn-Klomberg AL, Bouma M, et al. Tijdsbesteding in de huisartsenpraktijk. Huisarts en Wetenschap [Time use in general practice]. 2012; 55: 542-547. https ://doi.org/10 $.1007 / \mathrm{s} 12445-012-0276-3$

[2] Van den Hombergh P, Künzi B, Elwyn G, et al. High workload and job stress are associated with lower practice performance in general practice: an observational study in 239 general practices in the Netherlands. BMC Health Services Research. 2009; 9: 118. PMid:19604386. https://doi .org/10.1186/1472-6963-9-118

[3] Van Ham I, Verhoeven AA, Groenier KH, et al. Job satisfaction among general practitioners: a systematic literature review. The European Journal of General Practice. 2006; 12: 174-180. PMid:17127604. https://doi.org/10.1080/13814780600994 376

[4] Van den Berg MJ. Workload in general practice. PhD Thesis, University of Tilburg, The Netherlands, 2010. Available from: https://www.nivel.nl/sites/default/files/besta nden/Proefschrift-Michael-van-den-Berg.pdf

[5] Van Greuningen M. Health workforce planning in the Netherlands: How a projection model informs policy regarding the general practitioner and oral health care workforces. $\mathrm{PhD}$ Thesis, University of Tilburg, 2016. Available from: https://www.nivel.nl/sites/default/files/bestanden /Health_workforce_planning_Netherlands.pdf

[6] Hall TL. Why plan human resources for health? Human Resources Development Journal. 1998; 2: 77-86.

[7] Ono T, Lafortune G, Schoenstein M. Health Workforce Planning in OECD Countries: A Review of 26 Projection Models from 18 Countries. Report, OECD Publishing, France, June 2013. Available from: https://ideas.repec.org/p/oec/elsaad/62-en.html

[8] Capaciteitsorgaan. Capaciteitsplan 2016: Voor de medische, tandheelkundige, klinisch technologische, geestelijke gezondheid-, en aanverwante (vervolg)opleidingen. Deelrapport 2 Huisartsgeneeskunde [Capacity plan 2016 for GP care]. Report, Capaciteitsorgaan, The Netherlands, October 2016. Available from: https://capaciteitsorgaan.nl/app/uploads/2016/10/2 016_10_21-Capaciteitsplan-2016-Deelrapport-2-Huisa rtsgeneeskunde-DEFINITIEF.pdf

[9] Van den Berg WN, Nobel JC, Post-Wijma S. Tijd voor zorg. Meetweek 2012: 19-25 mei, 2-8 juni [Time for care. Weeks of measurements 2012: 19th to 25th of May and 2nd to 8th of June].
Report, VPHuisartsen, The Netherlands, September 2013. Available from: http://www.vphuisartsen.nl/wordpress/wp-c ontent/uploads/2013/12/VPH-Meetweek-2012.pdf

[10] Jurling B, Koster L, Batterink M, et al. Praktijkkosten- en inkomensonderzoek huisartsenzorg [Research of practice costs and income in general practice]. Report, Nederlandse Zorgautoriteit (Nza), The Netherlands, September 2012. Available from: http://docplayer.nl/10055262-Praktijkkosten-e n-inkomensonderzoek-huisartsenzorg.html

[11] Bradburn NM, Rips LJ, Shevell SK. Answering autobiographical questions: The impact of memory and inference on surveys. Science. 1987; 236: 157-161. PMid:3563494. https://doi.org/10.112 $6 /$ science. 3563494

[12] Stoop IAL. The hunt for the last respondent. Nonresponse in sample surveys. Report, Social and Cultural Planning Office of the Netherlands, The Netherlands, May 2005. Available from: https : //dspace.library.uu.nl/handle/1874/2900

[13] Kelley K, Clark B, Brown V, et al. Good practice in the conduct and reporting of survey research. International Journal for Quality in Health Care 2003; 15: 261-266. PMid:12803354. https : //doi.org/10.1093/intqhc/mzg031

[14] Van den Berg B, Spauwen P. Measurement of informal care: an empirical study into the valid measurement of time spent on informal caregiving. Health Economics. 2006; 15: 447-460. PMid:16389664 https://doi.org/10.1002/hec.1075

[15] Bolger N, Davis A, Rafaeli E. Diary methods: Capturing life as it is lived. Annual Review of Psychology. 2003; 54: 579-616. PMid:12499517. https://doi.org/10.1146/annurev.psych 54.101601 .145030

[16] Van Hassel DTP, Van der Velden LFJ, Batenburg RS. Landelijk SMS-tijdsbestedingsonderzoek huisartsen [National time use research among GPs based on SMS text messaging]. Report, NIVEL, The Netherlands, November 2014. Available from: https://www. nivel.nl/sites/default/files/bestanden/Rapport-Lan delijk-SMS-tijdsbestedingsonderzoek-huisartsen.pdf

[17] Van Hassel DTP, Batenburg R, Van der Velden L. Voorstudie voor een SMS-gebaseerd tijdsbestedingsonderzoek (TBO) onder huisartsen [Pilot study of an SMS based time use research among GPs]. Report, NIVEL, The Netherlands, June 2013. Available from: https: //www.nivel.nl/sites/default/files/bestanden/Rappo rt-sms-gebaseerd-tijdsbestedingsonderzoek.pdf

[18] Van Hassel DTP, Kasteleijn A, Kenens RJ. Cijfers uit de registratie van huisartsen: Peiling 2013 [Figures of the registration of GPs in 
2013]. Report, NIVEL, The Netherlands, March 2014. Available from: https://www.nivel.nl/sites/default/files/besta nden/Cijfers-uit-de-registratie-van-huisartsen-pei ling-jan-2013.pdf

[19] European Commission, International Monetary Fund, Organisation for Economic Co-operation and Development, United Nations, World Bank. System of National Accounts 2008. New York: United Nations; 2009. 410 p.

[20] Koch K, Miksch A, Schürmann C, et al. The German health care system in international comparison. Deutsches Ärzteblatt International. 2011; 108: 255-261. https://doi.org/10.3238/arzteb 1. 2011.0255
[21] Schäfer W, Van den Berg M, Groenewegen P. De werkbelasting van huisartsen in internationaal perspectief [Workload of Dutch GPs from an international perspective]. Huisarts en wetenschap. 2016; 59: 94-101. https://doi.org/10.1007/s12445-016-0065-5

[22] Actiecomité Het Roer Moet Om [Free translation: We need a radical change]. Available from: www.hetroermoetom.nu (2018, accessed 27th of June, 2018)

[23] Lako CJ, Van den Hombergh P, Honingh ME, et al. Huisartsen over marktwerking, werkdruk en kwaliteit van zorg [GPs on managed competition, job stress and quality of care]. Tijdschrift voor gezondheidswetenschappen. 2014; 92: 19-21. https ://doi .org/10.100 $7 /$ s12508-014-0010-6 